Research Article

\title{
Compressional Physics of Binary Mixture of Dried Andrographis paniculata and Moringa oleifera Leaves
}

Johnson Ajeh Isaac 1*
Kokonne Elizabeth Ekere 10
Ekeh Ezekiel 1
Isa Hayatu Galadima ${ }^{\text {10 }}$
Rashida Abdulahi 1
Ayuba Samali ${ }^{2}$
1Department of Pharmaceutical
Technology and Raw Materials
Development, National Institute for
Pharmaceutical Research
Development, Abuja, Federal Capital
Territory, Nigeria
2Department of Medicinal Chemistry
and Quality Control, National Institute
for Pharmaceutical Research and
Development, Abuja, Federal Capital
Territory, Nigeria
*email: ajeh.johnson@niprd.gov.ng
Keywords:
Andrographis paniculata
Heckel
Kypertension
Moringa oleifera

\begin{abstract}
Traditionally, the leafy part of Andrographis paniculata and Moringa oleifera have been widely reported to manage hypertension. Investigation of its pharmacological actions justifies its use. As part of formulation studies to standardize them, this study focused on their compaction and compression properties. Compacts equivalent to 250 $\mathrm{mg}$ of A. paniculata and M. oleifera were produced by compressing powders and granules at various compression pressure. Results show that $M$. oleifera met the WHO limit for ash values. Relative density values for granulated batches were higher, while their moisture content values were lower when compared to those of direct compression. The result from Heckel plots shows that batches deform mainly by plastic flow. For Kawakita plots, values of $1 / \mathrm{b}$ show that batches containing microcrystalline cellulose were less cohesive. The plot of tensile strength signifies that granulated batches achieved maximum crushing strength faster at low pressure. Formulations containing maize starch were shown to have higher percent porosity, and granulated batches gave higher values for apparent densitypressure relationship and lower friability values. Tablets produced by the wet granulation method showed better compression and compaction properties than those formulated by direct compression.
\end{abstract}

Received: August 8th, 2021

Accepted: October 31th 2021

Published: November 30th, 2021

(c) 2021 Johnson Ajeh Isaac, Kokonne Elizabeth Ekere, Ekeh Ezekiel, Isa Hayatu Galadima, Rashida Abdulahi, Ayuba Samali. Published by Institute for Research and Community Services Universitas Muhammadiyah Palangkaraya. This is an Open Access article under the CC-BY-SA License (http://creativecommons.org/licenses/by-sa/4.0/). DOI: https://doi.org/10.33084/bjop.v4i4.2544

\section{INTRODUCTION}

The use of herbs for medicinal, nutritional, and economic benefits is increasing globally because they are easier to obtain, more affordable, and often exhibit minor side effects than conventional medicines. Formulating them into suitable dosage forms will not only increase their acceptability but will also improve their stability. Hence, a proper understanding of how herbal powders behave during compaction and compression is necessary to overcome dosage form and dosing challenges ${ }^{1,2}$.
Tablets are by far the most frequently used dosage form for all active medicinal ingredients. They have advantages for both manufacturer and user: ease of administration, the convenience of administration, and accurate dosing make it a versatile and popular dosage form $^{3}$. The ability to predict the mechano-structural attributes of tablets based on their raw material properties and process parameters is challenging due to poor understanding of the complex nature of the powder compaction process linked to parameters like 
deformation behavior, particle size and shape, compression stress, particle rearrangement, as well as elastic and plastic deformation of single particles and particle fragmentation ${ }^{4}$. This calls for a systematic and thorough characterization of raw materials' compression and compaction behavior as a prerequisite for a rationally based formulation and process development.

The ability of a powder bed to produce a strong tablet mechanically is called compactibility, while compressibility has to do with how a powder bed is compressed and consequently reduces volume ${ }^{5}$. Compaction and compression play a key role in manufacturing tablets, granules, and powder handling. The study of powder technology has continued to evolve by the need of the herbal industries ${ }^{6}$.

Andrographis paniculata (Figure 1) is an ancient oriental and ayurvedic plant belonging to the Angiosperm division, Dicotyledon class, Gamopetalae subclass, Bicarpellatae series, Personales order, Acanthaceae family, Acanthoideae subfamily, Justiciae tribe, Andrographideae subtribe, and has about 40 different species $^{7}$. It is an annual, branched, and erect plant of about $1 \mathrm{~m}$ high indigenous to the Indian peninsula, Sri Lanka, and cuts across Southeast Asia's different regions ${ }^{8}$. The leaves/aerial part treats colic pain, loss of appetite, hepatitis, tuberculosis, cough, mouth ulcer, bronchitis, diarrhea, pyrexia, hypertension, diabetes, cancer, and urinary tract infection ${ }^{9,10}$. Studies have shown that $A$. paniculata could reduce angiotensin-converting enzymes and reactive oxygen species activities in spontaneously hypertensive rats ${ }^{11}$. In isolated rats, it has been shown to decrease coronary perfusion pressure. The crude extract was able to induce dramatic hypotensive effects and inhibit the influx of $\mathrm{Ca}_{2}{ }^{+}$through receptor and voltagegated $\mathrm{Ca}_{2}{ }^{+}$channels in hypertensive rats ${ }^{12}$. Aside from its anti-inflammatory and anti-oxidant activities, $A$. paniculata could also inhibit the activation of $\mathrm{NFKB}^{13}$.
When compared to propranolol, its anti-hypertensive activity was shown to be higher in cats ${ }^{14}$. The ethanolic herb extract of $A$. paniculata induced hypertensive activity in phenylephrine-induced hypertensive rats ${ }^{15}$.

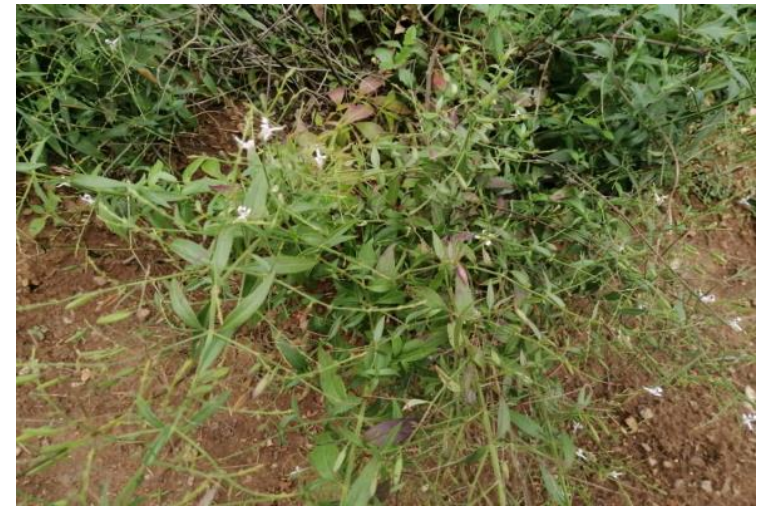

Figure 1. Andrographis paniculata plant

Moringa oleifera (Figure 2) belongs to the Magnoliophyte division, Magnoliopsida class, Capparales order, and Moringaceae family, having up to 13 species from tropical and subtropical climates ${ }^{16}$. It is native to Africa and Asia. A perennial plant with about $15 \mathrm{~m}$ height has a diameter of about $40 \mathrm{~cm}^{17}$. The leafy part has been demonstrated to have antihypertensive, anti-diabetic, anti-malarial, and anti-typhoid properties $^{18}$. The methanolic and ethyl acetate extracts decreased systolic blood pressure in nitro-arginine methyl ester-induced hypertensive mice ${ }^{19}$. The leaf of $M$. oleifera reduced systolic and diastolic pressure in hypertensive males aged between 35-50 years ${ }^{20}$. The aqueous extract of $M$. oleifera reduced intraocular and blood pressure of normotensive adults after 60 minutes of administration ${ }^{21}$.

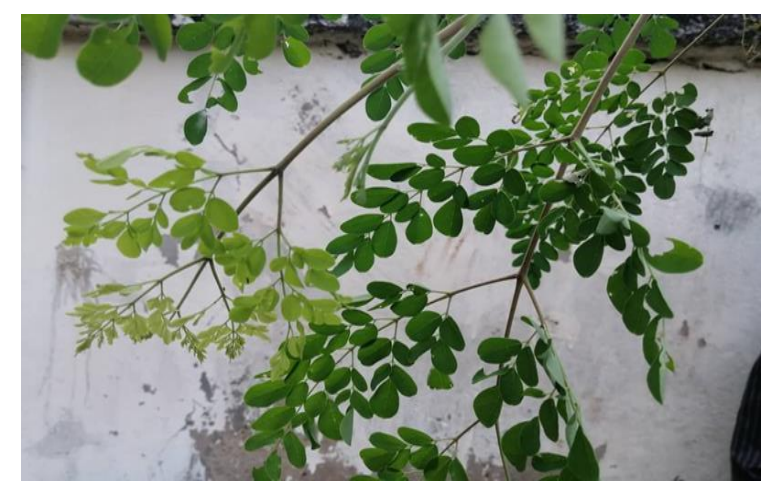

Figure 2. Moringa oleifera plant 
In an effort to standardize herbal anti-asthmatic agent (AA1), the effects of some channeling agents on the compaction properties of the mixed stem bark extract of Anogeissus leiocarpus and Prosopis africana were evaluated using the Heckel equation. None of the channeling agents used were seen to alter their compaction properties significantly 22 . In another study, Heckel, Kawakita, and Walker's model were proven suitable while discussing the properties of the freeze-dried herbal extract from A. paniculata, Eurycoma longifolia, and Orthosiphon stamineus ${ }^{23}$. In a similar work ${ }^{24}$, compressional properties of three selected Malaysian herbs (E. longifolia, Ficus deltoidea, and Morinda citrifolia) were evaluated using microcrystalline cellulose as a binder. Moringa oleifera and spirulina complex were successfully co-formulated to produce a nutraceutical tablet using the direct compression method ${ }^{25}$. The micromeritics of the polyherbal dispersible tablet for managing kidney disorders in geriatric patients has been proven to have good flow properties ${ }^{26}$.

This study discussed the properties of such herbal extract powder from A. paniculata and M. oleifera. It focused on the characterization of compaction and compression of a binary mixture of $A$. paniculata and $M$. oleifera leaf powder as part of formulation studies to standardize them since most work conducted on these herbs are limited to their chemical and medicinal properties. This will help determine the technical feasibility and economic viability of producing solid oral dosage forms of these herbs via direct compression or wet granulation methods. Both plants have been widely reported in managing hypertension traditionally. Administration of two or more complementary antihypertensive in fixed doses is always linked to greater efficacy with reduced dosedependent side effects and adverse reactions when compared to monotherapy ${ }^{27,28}$. When smaller doses of medicines with a different mechanism of action are combined, a synergistic effect is achieved, patient convenience and compliance is enhanced, the response rate is improved, dosing becomes more appropriate, alteration in pharmacokinetic becomes favorable, and the cost is reduced ${ }^{27-29}$

\section{MATERIALS AND METHODS}

\section{Materials}

Andrographis paniculata and M. oleifera leaves were collected from the National Institute for Pharmaceutical Research and Development (NIPRD) botanical garden. Identification and authentication of the plants were done by Mr. Akeem Lateef of the Herbarium unit of the Institute and given voucher numbers NIPRD/H/7263 and NIPRD/H/7265 for A. paniculata and M. oleifera, respectively. They were washed with distilled water, oven-dried at $40^{\circ} \mathrm{C}$ for six hours, and milled to a coarse powder. This was passed through a $150 \mu \mathrm{m}$ sieve, transferred into a plastic container, and stored in a desiccator containing silica gel for further analysis. Instruments and other materials used include Tableting machine-94305 (Manesty, China), StampfvolumeterSTAV 2003 (Engelsmann, Germany), digital moisture analyzer (Ohaus, US), micrometer screw gauge-IDC1012EB (Mitutoyo, Japan), analytical weighing balanceAB54 (Mettler Toledo, Switzerland), tablet hardness tester-D6072 (Erweka, Germany), friabilator-TA (Erweka, Germany), magnesium stearate, and talc (BDH, UK).

\section{Methods}

\section{Determination of ash values}

Total ash, water-soluble ash, and acid-insoluble ash to establish the quality and purity of the powdered plant materials were determined by the methods reported from previous research ${ }^{30}$. 


\section{Granulation}

Four batches of the powdered materials were prepared by either direct or wet granulation methods. For the batch mixture of $A$. paniculata and $M$. oleifera powders containing maize starch as binder and disintegrant (ABMP), $125 \mathrm{mg}$ of A. paniculata and $125 \mathrm{mg}$ of M. oleifera were mixed to give a homogenous mixture to be compressed directly using 5 and $10 \%$ maize starch as binder and disintegrant. The mixture of $A$. paniculata and M. oleifera powders containing microcrystalline cellulose (MCC) starch as binder and disintegrant (ABMCP) was the same as ABMP, but MCC was incorporated in place of maize starch as binder and disintegrant. For the granulated mixture of $A$. paniculata and $M$. oleifera powders containing maize as binder and disintegrant (ABMG), the mixture of the ingredients was the same as that of ABMP but was wetted with a prepared maize starch mucilage and the wet mass forced through a 599 $\mu \mathrm{m}$ screen granulating sieve. The granules were ovendried at $40^{\circ} \mathrm{C}$ for an hour. The dried granules were again passed through a $599 \mu \mathrm{m}$ screen to break up agglomerates. The batch granulated mixture of $A$. paniculata and $M$. oleifera powders containing MCC as binder and disintegrant (ABMCG) was the same as ABMG with MCC substituted for maize starch.

\section{Determination of flow properties and densities}

Bulk density (BD) was determined by placing $20 \mathrm{~g}$ of powdered sample into a weighed $50 \mathrm{~mL}$ graduated measuring cylinder. For tapped density (TD), a measuring cylinder filled with powdered material was tapped until a constant volume was reached using a tapped density machine. True density (TrD) was determined by a method described elsewhere using liquid paraffin as the displacement fluid ${ }^{2}$. Relative density $(\mathrm{RD})$ of the materials was determined using the ratio of tapped density to particle density. The angle of repose (AR) was determined based on the fixed funnel and free-standing cone method. Hausner ratio (HR) was calculated as the ratio of tapped density to bulk density; while Carr index $(\mathrm{CI})$ was evaluated using the difference between bulk density and tapped density to the ratio of tapped density; and porosity $(\mathrm{P})$ was determined as the ratio of void volume (VV) to $\mathrm{BD}$, where $\mathrm{VV}$ is the difference between $\operatorname{TrD}$ and $\mathrm{BD}$. The moisture content was determined using a digital moisture analyzer set at $105^{\circ} \mathrm{C}$. All measurements were in triplicates and presented as mean and standard deviations.

\section{Compaction}

Compacts equivalent to $250 \mathrm{mg}$ of samples A. paniculata and $M$. oleifera were produced by compressing powders and granules for 60 seconds at various compression pressure with the aid of a Manesty tableting machine, with the basic components of tablets were presented in Table I. The uniaxial die was attached to the upper moving crosshead of the machine. Compression was made by lubricating the die and punches with $1 \% \mathrm{w} / \mathrm{v}$ dispersion of magnesium stearate in chloroform at room temperature with a relative humidity of about $75 \%$. Fifty tablets were compressed at each pressure. The compressed tablets were wrapped in a polythene bag and stored in a desiccator containing silica gel for 24 hours to allow elastic recovery and hardening. The tablets' diameter, height, mass, and volume were measured using a micrometer screw gauge to obtain the density before and after compression to observe for signs of plastic recovery, hardening, and to prevent false lowyield values. Weight variation was determined using the analytical weighing balance, and the crushing strength was evaluated using a tablet hardness tester. This information was used to determine values for tensile strength (Equation 1) and data for validation of Heckel and Kawakita models. Friability was determined using a friabilator, set at $25 \mathrm{rpm}$ for 4 minutes. 
Table I. Basic tablet component

\begin{tabular}{lr}
\hline \multicolumn{1}{c}{ Ingredients } & Weight (mg) \\
\hline Andrographis paniculata & 125 \\
Moringa oleifera & 125 \\
Binder & 12.5 \\
Disintegrant & 25 \\
Magnesium stearate & 1 \\
Talc & 0.5 \\
\hline Total & $\mathbf{2 8 9}$ \\
\hline
\end{tabular}

$$
\mathrm{TS}=2 \mathrm{CS} / \pi \mathrm{dt} \quad[1]
$$

TS: tensile strength; CS: crushing strength $(\mathrm{kgF})$; $\mathrm{d}$ : diameter of the tablet (mm); t: thickness of the tablet (mm)

\section{Model}

Heckel model expresses the volume of reduction mechanism under compression force by relating the relative density of the powder bed during compression to the applied pressure. This model assumes that powder compression obeys first-order kinetics with interparticle pores as the reactants and densification of the powder as the product ${ }^{31}$, as represented in Equation 2.

$$
\ln \left[\frac{1}{1-\mathrm{D}}\right]=\mathrm{KP}+\mathrm{A}[2]
$$

Plotting a graph of $\ln [1 /(1-D)]$ against the applied pressure $\mathrm{P}$, values of $\mathrm{K}$ and $\mathrm{A}$ could be obtained from the slope and intercept, respectively. The slope of the straight-line plot $\mathrm{K}$ was the reciprocal of the material's mean yield pressure $\left(\mathrm{P}_{\mathrm{y}}\right)$. The relative density $\left(\mathrm{D}_{\mathrm{A}}\right)$ could be obtained from intercept A (Equation 3):

$$
\mathrm{D}_{\mathrm{A}}=1-\mathrm{e}^{-\mathrm{A}}[3]
$$

The relative density of the material when the pressure was zero $\left(D_{0}\right)$ was the initial rearrangement of densification due to die filling. The relative density $\left(D_{B}\right)$ was the phase rearrangement at low pressure, and it was the difference between $\mathrm{D}_{\mathrm{A}}$ and $\mathrm{D}_{0}$ (Equation 4):

$$
\mathrm{D}_{\mathrm{b}}=\mathrm{D}_{\mathrm{A}}-\mathrm{D}_{0} \quad[4]
$$

Based on the deformation properties described by Heckel, materials were type A if a linear relationship was observed at all the applied pressures indicating densification only by plastic deformation. If a linear one follows an initial curved region, it implies type B. For type
C, an initial steep linear region becomes superimposed and flattened at increased pressure ${ }^{32}$.

Kawakita model has received considerable attention in powder compaction, relating the volume of reduction of the powder column to the number of taps, as represented in Equation 5.

$$
\frac{\mathrm{N}}{\mathrm{C}}=\frac{\mathrm{N}}{\mathrm{a}}+\frac{1}{\mathrm{ab}}[5]
$$

In which $a$ and $b$ were constants; $a$ : describing the degree of volume reduction at the limit of tapping and was called compactibility; while $1 / b$ was considered a constant relating to cohesion and was called cohesiveness. Numerical values for constants a and $1 / b$ were obtained from the slope of plots of N/C versus the number of taps $\mathrm{N}^{33}$.

\section{RESULTS AND DISCUSSION}

\section{Ash values}

Ashing determines the purity and quality of powdered material by measuring the total amount of inorganic components of material after ignition or complete oxidation. It indicates the types/concentration of minerals, taste, appearance, texture, and stability of material related to the safety of the material. From our

\begin{tabular}{|c|c|c|c|}
\hline Samples & $\begin{array}{c}\text { Total ash } \\
(\% w / w)\end{array}$ & $\begin{array}{c}\text { Water- } \\
\text { soluble ash } \\
(\% \mathrm{w} / \mathrm{w})\end{array}$ & $\begin{array}{c}\text { Acid- } \\
\text { insoluble ash } \\
(\% \mathrm{w} / \mathrm{w})\end{array}$ \\
\hline A. paniculata & $9.27 \pm 0.04$ & $6.83 \pm 0.02$ & $1.60 \pm 0.02$ \\
\hline M. oleifera & $5.56 \pm 0.03$ & $4.73 \pm 0.02$ & $0.43 \pm 0.02$ \\
\hline $\begin{array}{l}\text { A. paniculata } \\
+ \text { M. oleifera }\end{array}$ & $12.27 \pm 0.01$ & $10.63 \pm 0.06$ & $1.54 \pm 0.02$ \\
\hline WHO Limits & $<8.0$ & - & $<1.0$ \\
\hline
\end{tabular}
study, M. oleifera met World Health Organization (WHO) specifications, as shown in Table II. The presence of impurities could make a sample not meet specifications for ash values.

\section{Flow properties}

The flow properties of the samples were presented in Table III. Suitable flow property was necessary to ensure 
proper die fill during compression. The powders exhibited poor flow $\left(\mathrm{AR}>50^{\circ}\right)$, while the granules demonstrated reasonable flow potentials $\left(\mathrm{AR}<35^{\circ}\right)$. This underscores the cohesive nature of the powders. The flow rate of the powders and those of the granules were seen to be significantly different. These differences in values favor the granules over the powders in tableting. High moisture content, many fines, and electrostatic charges can cause a powder not to have a good flow behavior ${ }^{34,35}$.

Bulk and tapped density relationships are another way to index flowability. Batches containing maize starch as binder and disintegrant were seen to have higher bulk densities than those with MCC. This may be due to the cohesive nature of maize starch. Similarly, increased tapped density for all batches implies better compactibility due to applied pressure ${ }^{36}$.

Hausner ratio relates bulk density to tapped density ${ }^{37}$. All batches have values greater than 1.2 except ABMCG, indicating poor flow attributes. Carr index value for ABMG shows good flow property while others have fair flow properties. However, CI being a one-point determination may not always predict the ease or speed with which the powder or granules consolidate, as some materials with high CI will consolidate rapidly in the tableting machine die cavity ${ }^{38}$. The true density of a material can relates the tabletability profile of a material to the interparticle bonding strength. However, similarity in true density does not necessarily mean similarity in tabletability. An increase in granule filling density impacts tabletability and compactability and limits the ability to achieve tablets of adequate mechanical strength ${ }^{39}$. This is why the batches produced through direct compression in this study did not have adequate mechanical stability, as seen in the friability test.

Moisture content, a key determining factor in tablet stability, was seen to be lower in granulated batches and relatively higher in those of direct compression. This explains why the granulated batches had a better flow ${ }^{40}$. Moisture plays a key role in interparticle bond formation by increasing the tensile strength of the powder bed and decreasing density variation within the tablet. Moisture increases plastic deformation, decreases elastic properties of materials, and reduces ejection force ${ }^{41}$.

Table III. Flow properties

\begin{tabular}{|c|c|c|c|c|c|c|c|c|c|}
\hline $\begin{array}{l}\text { ज̃ } \\
\text { స̃ }\end{array}$ & $\frac{\overparen{e}}{\sum}$ & 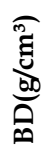 & 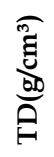 & 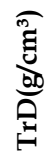 & 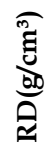 & 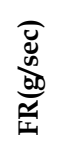 & $\underset{\nwarrow}{\widetilde{\sigma}}$ & 吉 & $\frac{\widehat{e}}{\mathrm{e}}$ \\
\hline$\sum_{\substack{\infty \\
\&}}^{E}$ & 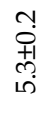 & 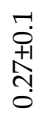 & $\begin{array}{l}m \\
0 \\
0+1 \\
0 \\
0 \\
0 \\
0\end{array}$ & \begin{tabular}{l} 
Na \\
0 \\
+1 \\
\multirow{+}{+}{} \\
0
\end{tabular} & $\begin{array}{l}m \\
0 \\
01 \\
+1 \\
10 \\
0 \\
0\end{array}$ & $\begin{array}{l}\overrightarrow{0} \\
\stackrel{0}{+1} \\
\stackrel{1}{0} \\
\stackrel{0}{0}\end{array}$ & $\begin{array}{l}\stackrel{m}{0} \\
\stackrel{10}{n}\end{array}$ & $\stackrel{m}{\stackrel{m}{r}}$ & $\stackrel{\mathscr{N}}{\mathrm{N}}$ \\
\hline$\sum_{\substack{\infty \\
\&}}^{0}$ & $\begin{array}{l}\tilde{n} \\
\stackrel{+}{1} \\
\hat{n} \\
\infty\end{array}$ & $\begin{array}{l}\stackrel{-}{0} \\
\stackrel{+}{+1} \\
\stackrel{m}{0} \\
0\end{array}$ & 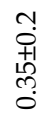 & $\begin{array}{l}\text { न.. } \\
\text { +1 } \\
\text { ले } \\
0 .\end{array}$ & 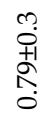 & $\begin{array}{l}\text { - } \\
0 \\
+1 \\
0 \\
0 \\
0\end{array}$ & $\begin{array}{l}\text { \&? } \\
\text { க) }\end{array}$ & 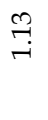 & $F$ \\
\hline$\sum_{\substack{0 \\
\&}}^{0}$ & $\begin{array}{l}-1 \\
0 \\
+1 \\
\infty \\
+ \\
+\end{array}$ & 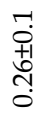 & $\begin{array}{l}\text { Nִ } \\
0 \\
+1 \\
10 \\
0 \\
0\end{array}$ & 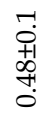 & $\begin{array}{l}\stackrel{-}{0} \\
+ \\
+1 \\
10 \\
0\end{array}$ & $\begin{array}{l}n \\
0 \\
+1 \\
0 \\
\stackrel{0}{0} \\
0\end{array}$ & $\begin{array}{l}8 \\
\text { तิ } \\
\text { กิ }\end{array}$ & $\begin{array}{l}\text { ஸे } \\
\stackrel{\text { m}}{r}\end{array}$ & $\stackrel{\sim}{\sim}$ \\
\hline$\sum_{\substack{0 \\
\ll}}^{0}$ & $\begin{array}{c}\tilde{n} \\
0 \\
+1 \\
10 \\
\infty\end{array}$ & 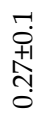 & 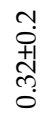 & 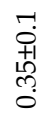 & $\begin{array}{c}\overrightarrow{-} \\
\stackrel{0}{+1} \\
\stackrel{1}{1} \\
\hat{0}\end{array}$ & 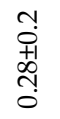 & $\begin{array}{l}\infty \\
\text { கే } \\
\text { లో }\end{array}$ & 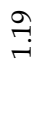 & $\stackrel{0}{\sim}$ \\
\hline
\end{tabular}

Values were expressed as mean \pm SD of $n=6$ where applicable.

\section{Compaction and compression properties}

The slopes for the Heckel plot (Figure 3) increased proportionally for all the formulations as the compression pressure increased. This shows that the densification rate of the batches reduces with an increase in the force of compression ${ }^{40}$. As compression progresses, the linearity obtained shows that plastic deformation occurs. The lack of a discernible initial curved region shows different fragmentation stages; hence, the batches were deformed mainly by plastic flow ${ }^{42}$. Our work also revealed that the compaction behavior of ABMCG was characterized by a lower degree of plastic deformation when compared to ABMG, and this may be as a result of the brittle nature of MCC, which increases hardness and makes it more resistant to plastic deformation. Hence, a higher yield was required to initiate deformation. 


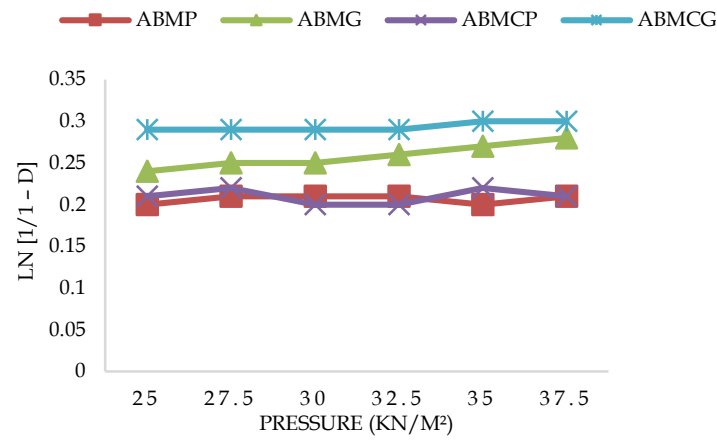

Figure 3. Heckel plots for compacts produced

Values of $\mathrm{D}_{0}$ obtained for all batches show weak electrostatic forces preventing the packaging of particles in the recompression stage ${ }^{40,43}$. Slightly higher values of $\mathrm{D}_{0}$ for granulated batches imply that the degree of initial packing in the die due to die filling is greater than those of direct compression (Table IV). The excipient type did not significantly affect the degree of packing, as no trend was observed. A higher value of $\mathrm{D}_{\mathrm{A}}$ for powders indicates a greater degree of fragmentation. When pressure is low, the large materials are fractured into small ones, further enhancing rearrangement. The larger the slopes, the greater the degree of plasticity of materials. Powders were more resistant to movement once the initial packing phase had been completed. This could be due to high cohesive forces, likely due to their amorphous nature ${ }^{44}$. $D_{B}$ explains the particle rearrangement phase in the consolidation process of the batches. Values of $D_{B}$ were higher than those of $D_{0}$, and this indicates the presence of fragmentation of granules at the applied pressures ${ }^{43}$.

Table IV. Heckel and Kawakita parameters

\begin{tabular}{lcccccc}
\hline Batch & $\mathbf{P}_{\mathbf{y}}$ & $\mathbf{D}_{\mathbf{A}}$ & $\mathbf{D}_{\mathbf{0}}$ & $\mathbf{D}_{\mathbf{B}}$ & $\mathbf{a}$ & $\mathbf{1 / b}$ \\
\hline ABMP & 1666.7 & 0.81 & 0.27 & 0.54 & 2.26 & 0.01 \\
ABMG & 129.9 & 0.80 & 0.31 & 0.49 & 2.68 & 0.01 \\
ABMCP & 20.6 & 1.00 & 0.26 & 0.74 & 4.76 & 0.003 \\
ABMCG & 434.8 & 0.75 & 0.27 & 0.48 & 4.46 & 0.007 \\
\hline
\end{tabular}

$\mathrm{P}_{\mathrm{y}}$ : mean yield pressure values of the formulations; $\mathrm{D}_{\mathrm{A}}$ : the total degree of densification occurring at the initial stages of compressions; $\mathrm{D}_{\mathrm{B}}$ : phase of particle rearrangement in the early compression stages, $D_{0}=$ degree of initial packing of the granules in the die as a result of filling; a: degree of volume reduction at the limit of tapping (compactibility); b: cohesiveness of the material
The mean yield to pressure, $\mathrm{P}_{\mathrm{y}}$ shows value in the following order: $\mathrm{ABMCP}<\mathrm{ABMG}<\mathrm{ABMCG}<\mathrm{ABMP}$. The results of this research were in line with the results of Haruna et al.5, who co-processed MCC with crospovidone for direct compression to yield an excipient with a lower degree of plastic deformation. High values of $\mathrm{P}_{\mathrm{y}}$ represent brittle materials, while low values imply that the materials underwent plastic deformation readily ${ }^{45}$.

The meager value of ABMCP may result from MCC being a material that forms extremes of the deformation spectrum. Compaction of the materials at higher pressures may extend powder densification, lowering the slope gradient, hence the increase in mean yield pressure values ${ }^{30}$. Wide variations in $\mathrm{P}_{\mathrm{y}}$ values across batches may be due to many factors such as the type of experiment, speed of compaction, compaction pressure, error in true density, the effect of regression coefficient on the gradient of the slope and particle size; these all affect derived values, and there is no standardization being set on these $\mathrm{e}^{46,47}$.

For the Kawakita plot as presented in Figure 4, the inverse relationship of the slope implies that the value of a decreases with an increase in slope values leading to better material compressibility. In other words, the smaller the values of $a$, the better the fluidity of the material ${ }^{46}$. Higher values of a for batches containing MCC correlate with its tendency to form poor compacts. Similarly, the value of $1 / b$ shows that batches with MCC are soft and can readily deform under pressure plastically. These findings imply that the interparticle force favoring compression was more petite and hence will probably result in the production of more friable tablets ${ }^{47}$. 


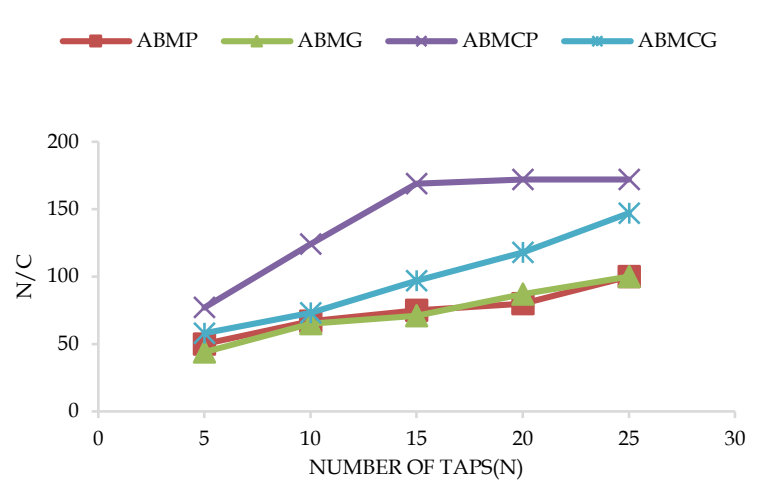

Figure 4. Kawakita plots for compacts produced

For the plot of tensile strength against pressure (Figure 5), granulated batches showed a similar trend of compression characteristics. Granulated batches achieved maximum crushing strength faster at low pressure than direct compression. It shows that granules can build a compact with higher strength than direct compression formulation. Due to reduced compressibility and compactibility, tablets of lower tensile strength were obtained with granulated batches. Tablets with relatively higher tensile strength were obtained with ABMCP because of MCC's good binding and tableting ability profile linked with its tendency to undergo plastic deformation during compression ${ }^{48}$.

Furthermore, particle size and shape have been shown to influence the contact surface area of the powder, which can influence the tablet's tensile strength ${ }^{49}$. Studies have shown that poly formulations have lower tensile strength than mono formulations due to adding one powder to another, which contaminates its particle surface and thereby decreases bonding among them ${ }^{46,47}$. Crushing strength seems to remain constant for granules irrespective of compression pressure, and this could be a hint for capping tendency as the pressure of compression increases. Variable internal tensions are generated, manifesting differently when crushing strength is evaluated. Generally, the tensile strength of all compacts was independent of the type of excipient used ${ }^{49}$.

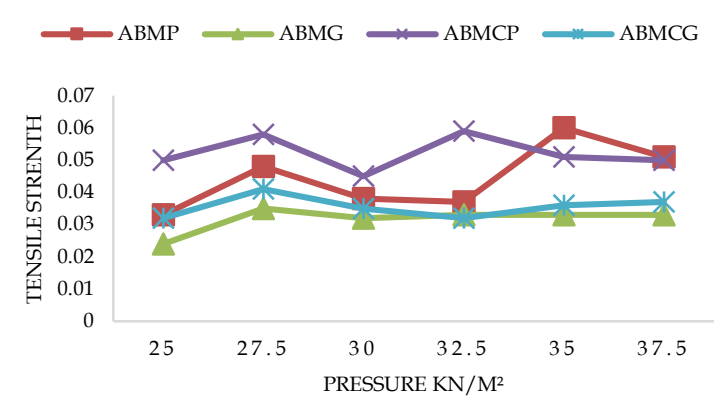

Figure 5. Effect of compression pressure on tensile strength of compacts

Our study's plot of porosity against pressure shows an inverse relationship (Figure 6). As the pressure of compression increases, percent porosity decreases. This underscores previous works 5 . When pressure is applied during compression of the powdered material, the voids or pores present within particles are removed, reducing the porosity of the given powder material ${ }^{14}$. Formulations containing maize starch were shown to have higher porosity than those containing MCC. This relationship also portrays a good picture of the compression properties of the formulations.

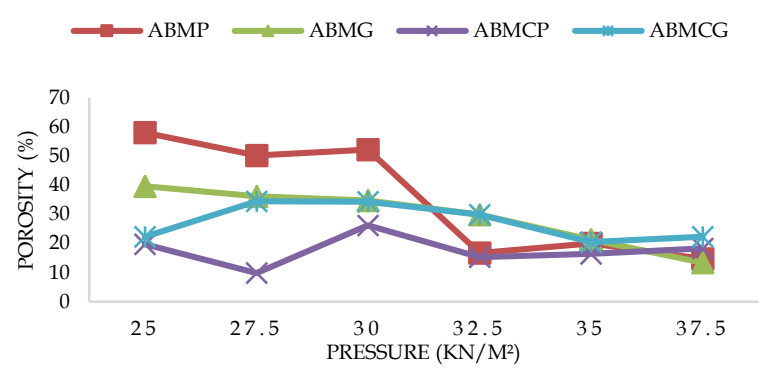

Figure 6. Effect of compression pressure on porosity of compacts

The relationship between apparent density versus pressure is linear, with granules having higher values than powder formulations (Figure 7). As the density increases, applied pressure increases. When a material undergoes compression at a given pressure, the air present among the powder particle is partially removed, and the particle becomes compact and closer to each other, thereby decreasing the bulk volume of the material ${ }^{49}$. 


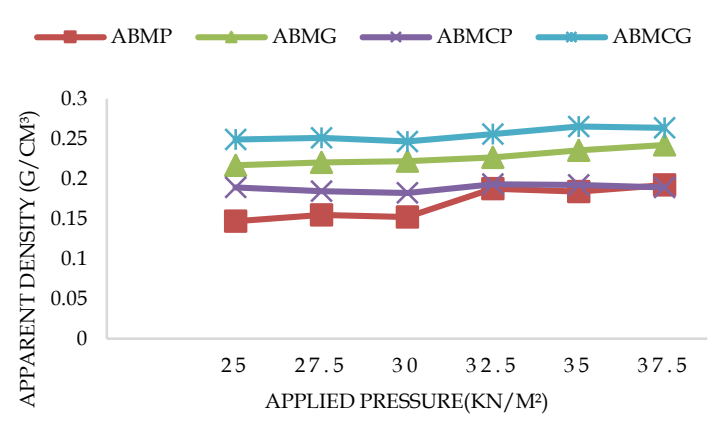

Figure 7. Effect of applied pressure on apparent density of the compacts

Friability is a compendium mechanical test with a specification of not more than $1 \%$. It is a surface deformation that is enhanced by the morphology of the tablet. The tablet should withstand attrition in a pack owing to partial powdering, chipping, or fragmentation during handling and transportation. Tablets with rough surfaces will be more friable than those with smooth surfaces. Moisture content, type, and concentration of excipients used could all affect friability ${ }^{49}$. Batches containing MCC granules had a better friability result, indicating mechanical stability, while batches for direct compressions did not meet specifications, as shown in Figure 8.

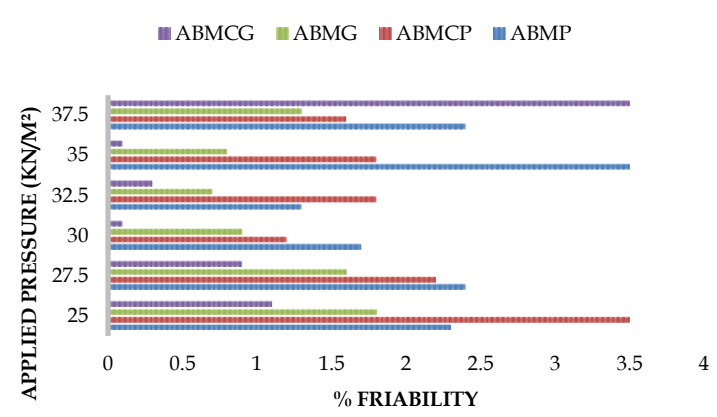

Figure 8. \%friability at different pressures

\section{CONCLUSION}

Wet granulation and direct compression method were utilized to formulate $\mathrm{AP}$ and MO leaf powder tablets. Although formulations were significantly different based on the type of excipients used, formulations from wet granulation showed better compression and compaction behavior. Fluctuations in plots could be as a result of several factors such as variations in size distributions and shape of the particles, nature of the API, the extent of particle rearrangement and fragmentation of the granules and powders, resistance of granules to densification, as well as type of bonding that exist between API and excipients. Optimization of process parameters such as granulation, moisture content, and compressional force can help achieve ideal biopharmaceutical properties in the tablet.

\section{ACKNOWLEDGMENT}

The authors are grateful to Mr. Ledou Gilama, Mr. Hassan Chama, and Mrs. Rekiya Akuboh of the Department of Pharmaceutical Technology and Raw Materials Development, National Institute for Pharmaceutical Research and Development, Nigeria, for their technical assistance in the laboratories while carrying out this study.

\section{AUTHORS' CONTRIBUTION}

All authors have an equal contribution in carrying out this study.

\section{DATA AVAILABILITY}

None.

\section{CONFLICT OF INTEREST}

The authors declare there is no conflict of interest whatsoever regarding this work.

\section{REFERENCES}

1. Sonnergaard JM. Investigation of a new mathematical model for compression of 
pharmaceutical powders. Eur J Pharm Sci. 2001;14(2):149-57. doi:10.1016/s0928-0987(01)00165-8

2. Ekor M. The growing use of herbal medicines: issues relating to adverse reactions and challenges in monitoring safety. Front Pharmacol. 2013;4:177. doi:10.3389/fphar.2013.00177

3. Adedokun MO, Ayorinde JO, Odeniyi MA. Compressional, mechanical and release properties of a novel gum in paracetamol tablet formulations. Curr Issues Pharm Medical Sci. 2015;27(3):187-94. doi:10.1515/cipms-2015-0013

4. Hooper D, Clarke FC, Mitchell JC, Snowden MJ. A Modern Approach to the Heckel Equation: The Effect of Compaction Pressure on the Yield Pressure of Ibuprofen and its Sodium Salt. J Nanomed Nanotechnol. 2016;7(3):1000381. doi:10.4172/21577439.1000381

5. Haruna F, Apeji YE, Oparaeche C, Oyi AR, Gamlen M. Future J Pharm Sci. 2020;6:35. doi:10.1186/s43094020-00055-9

6. Thapa P, Lee AR, Choi DH, Jeong SH. Effects of moisture content and compression pressure of various deforming granules on the physical properties of tablets. Powder Technol. 2017;310:97102. doi:10.1016/j.powtec.2017.01.021

7. Kushram A, Masih SK, Mir SA. Variation of Andrographolide Content in Andrographis paniculata from Different Sites of Balaghat Region of Jabalpur (M.P.). Int J Curr Res Rev. 2017;9(22):1-4. doi:10.7324/IJCRR.2017.9221

8. Hossain MS, Urbi Z, Sule A, Rahman KMH. Andrographis paniculata (Burm. f.) Wall. ex Nees: a review of ethnobotany, phytochemistry, and pharmacology. ScientificWorldJournal. 2014;2014:274905. doi:10.1155/2014/274905

9. Jarukamjorn K, Nemoto N. Pharmacological Aspects of Andrographis paniculata on Health and Its Major Diterpenoid Constituent Andrographolide. J Health Sci. 2008;54(4):370-81. doi:10.1248/jhs.54.370

10. Zhou J, Zhang S, Ong CN, Shen HM. Critical role of pro-apoptotic Bcl-2 family members in andrographolide-induced apoptosis in human cancer cells. Biochem Pharmacol. 2006;72(2):132-44. doi:10.1016/j.bcp.2006.04.019

11. Awang K, Abdullah NH, Hadi AHA, Fong YS. Cardiovascular activity of labdane diterpenes from
Andrographis paniculata in isolated rat hearts. J Biomed Biotechnol. 2012;2012:876458. doi:10.1155/2012/876458

12. Zhang CY, Tan BK. Hypotensive activity of aqueous extract of Andrographis paniculata in rats. Clin Exp Pharmacol Physiol. 1996;23(8):675-8. doi:10.1111/j.1440-1681.1996.tb01756.x

13. Das S, Periyasamy R, Pandey KN. Activation of IKK/NF-kB provokes renal inflammatory responses in guanylyl cyclase/natriuretic peptide receptor-A gene-knockout mice. Physiol Genomics. 2012;44(7):430-42. doi:10.1152/physiolgenomics.00147.2011

14. Mshelbwala K, Ofokansi KC, Kenechukwu FC. Antihypertensive Effect of Methanol Leaf Extract of Andrographis paniculata in Experimental Cats. Afr J Pharm Res Dev. 2013;5(2):109-20.

15. Jayakumar T,Hsieh CY, LeeJJ, Sheu JR. Experimental and Clinical Pharmacology of Andrographis paniculata and Its Major Bioactive Phytoconstituent Andrographolide. Evid Based Complement Alternat Med. 2013;2013:846740. doi:10.1155/2013/846740

16. Vergara-Jimenez M, Almatrafi MM, Fernandez ML. Bioactive Components in Moringa Oleifera Leaves Protect against Chronic Disease. Antioxidants. 2017;6(4):91. doi:10.3390/antiox6040091

17. Padayachee B, Baijnath $\mathrm{H}$. An overview of the medicinal importance of Moringaceae. J Med Plants Res. 2012;6(48):5831-9. doi:10.5897/JMPR12.1187

18. Woldekidan S, Mulu A, Ergetie W, Teka F, Meressa A, Tadele A, et al. Evaluation of Antihyperglycemic Effect of Extract of Moringa stenopetala (Baker $\mathrm{f}$.) Aqueous Leaves on Alloxan-Induced Diabetic Rats. Diabetes Metab Syndr Obes. 2021;14:185-92. doi:10.2147/DMSO.S266794

19. Acuram LK, Hernandez CLC, Popovich D. Antihypertensive effect of Moringa oleifera Lam. Cogent Biol. 2019;5(1):1596526. doi:10.1080/23312025.2019.1596526

20. Aekthammarat $D$, Pannangpetch $P$, Tangsucharit $P$. Moringa oleifera leaf extract lowers high blood pressure by alleviating vascular dysfunction and decreasing oxidative stress in L-NAME hypertensive rats. Phytomedicine. 2019;54:9-16. doi:10.1016/j.phymed.2018.10.023 
21. George GO, Ajayi OB, Oyemike AA. Effect of Moringa oleifera leaf aqueous extract on intraocular and blood pressure of normotensive adults in Edo State, Nigeria. J Niger Optometric Assoc. 2018;20(2):75-81.

22. Martins E, Christianah I, Amaka I, Olubunmi O. Effects of some channelling agents on the compaction properties of the mixed stem bark extracts of Anogeissus leiocarpus and Prosopis africana. J Med Herbs. 2017;8(1):9-14. doi:10.18869/JHD.2017.9

23. Yusof YA, Hamid AAA, Ahmad S, Razak NA, Ling CN, Mohamed S. A Comparison of the Direct Compression Characteristics of Andrographis paniculata, Eurycoma longifolia Jack, and Orthosiphon stamineus Extracts for Tablet Development. In: Ghrib T, editor. New Tribological Ways. London (UK): IntechOpen; 2011. p. 219-32. doi:10.5772/14967

24. Yusof YA, Chin NL, Anuar MS, Ahmad S, Abdullah $\mathrm{R}$, Nor CRM, et al. Tabletting characteristics of the selected Malaysian herbs. J Med Plants Res. 2012;6(43):5570-81. doi:10.5897/JMPR.9001177

25. Zheng Y, Zhu F, Lin D, Wu J, Zhou Y, Mark B. Optimization of formulation and processing of Moringa oleifera and spirulina complex tablets. Saudi J Biol Sci. 2017;24(1):122-6. doi:10.1016/j.sjbs.2016.08.017

26. Maurya H, Kumar T. Formulation, Standardization, and Evaluation of Polyherbal Dispersible Tablet. Int J Appl Pharm. 2019;11(1):158-67. doi:10.22159/ijap.2019v11i1.30113

27. Rodgers PT. Combination drug therapy in hypertension: a rational approach for the pharmacist. J Am Pharm Assoc. 1998;38(4):469-79. doi:10.1016/s1086-5802(16)30348-5

28. Maneesai P, Prasarttong P, Bunbupha S, Kukongviriyapan U, Kukongviriyapan V, Tangsucharit P, et al. Synergistic Antihypertensive Effect of Carthamus tinctorius L. Extract and Captopril in L-NAME-Induced Hypertensive Rats via Restoration of eNOS and ATR Expression. Nutrients. 2016;8(3):122. doi:10.3390/nu8030122

29. Sundström J, Gulliksson G, Wirén M. Synergistic effects of blood pressure-lowering drugs and statins: systematic review and meta-analysis. BMJ Evid Based Med. 2018;23(2):64-9. doi:10.1136/bmjebm2017-110888
30. Kadam VB, Momin RK, Wadikar MS, Tambe SS. Determination of water soluble Ash values of some Medicinal Plants of Genus Sesbania.J Pharm Biol Res. 2013;1(1):1-4.

31. ChattorajS, Sun CC. Crystal and Particle Engineering Strategies for Improving Powder Compression and Flow Properties to Enable Continuous Tablet Manufacturing by Direct Compression. J Pharm Sci. 2018;107(4):968-74. doi:10.1016/j.xphs.2017.11.023

32. Heckel RW. Density-pressure relationship in powder compaction. Trans Met Soc Aime. 1961;221:671-5.

33. Kawakita K, Lüdde KH. Some considerations on powder compression equations. Powder Technol. 1971. 4(2):61-8. doi:10.1016/0032-5910(71)80001-3

34. Liu LX, Marziano I, Bentham AC, Litster JD, White ET, Howes T. Effect of particle properties on the flowability of ibuprofen powders. Int J Pharm. 2008;362(1-2):109-17.

doi:10.1016/j.ijpharm.2008.06.023

35. Fassihi AR. Kanfer I. Effect of Compressibility and Powder Flow Properties on Tablet Weight Variation. Drug Dev Ind Pharm. 1986;12(11-13):1947-66. doi:10.3109/03639048609042619

36. Akhgari A, Sadeghi H, Dabbagh MA. Modification of flow and compressibility of corn starch using quasiemulsion solvent diffusion method. Iran J Basic Med Sci. 2014;17(8):553-9.

37. Silva JPS, Splendor D, Gonçalves IMB, Costa P, Lobo JMS. Note on the Measurement of Bulk Density and Tapped Density of Powders According to the European Pharmacopeia. AAPS PharmSciTech. 2013;14(3):1098-100. doi:10.1208/s12249-013-9994-5

38. Shanmugam S. Granulation techniques and technologies: recent progresses. Bioimpacts. 2015;5(1):55-63. doi:10.15171/bi.2015.04

39. Thoorens G, Krier F, Leclercq B, Carlin B, Evrard B. Microcrystalline cellulose, a direct compression binder in a quality by design environment-A review. Int J Pharm. 2014;473(1-2):64-72. doi:10.1016/j.jpharm.2014.06.055

40. Persson AS, Ahmed H, Velaga S, Alderborn G. Powder Compression Properties of Paracetamol, Paracetamol Hydrochloride, and Paracetamol Cocrystals and Coformers. J Pharm Sci. 2018;107(7):1920-7. doi:10.1016/j.xphs.2018.03.020 
41. Dominik M, Vraníková B, Svačinová P, Elbl J, PavlokováS, Prudilová BB, et al. Comparison of Flow and Compression Properties of Four Lactose-Based Co-Processed Excipients: Cellactose ${ }^{\circledR}$ 80, CombiLac ${ }^{\circledR}$, MicroceLac ${ }^{\circledR}$ 100, and StarLac ${ }^{\circledR}$. Pharmaceutics. 2021;13(9):1486. doi:10.3390/pharmaceutics13091486

42. Emeje MO, Isimi CY, Oqua DAN, Kunle OO. Some compaction characteristics of the hot water leaf extract og Nauclea latifiola: a potential antimalarial agent. J Herb Pharmacother. 2005;5(4):23-30.

43. Szumilo M, Belniak P,Swiader K, Holody E, Poleszak E. Assessment of physical properties of granules with paracetamol and caffeine. Saudi Pharm J. 2017;25(6):900-5. doi:10.1016/j.jsps.2017.02.009

44. Mohan S. Compression physics of pharmaceutical powders: A review. Int J Pharm Sci Res. 2012;3(6):1580-92.

45. Osamura T, Takeuchi $Y$, Onodera R, Kitamura M, Takahashi Y, Tahara K, et al. Formulation design of granules prepared by wet granulation method using a multi-functional single-punch tablet press to avoid tableting failures. Asian J Pharm Sci. 2018;13(2):113-9. doi:10.1016/j.ajps.2017.08.002

46. Doktorova M, LeVine MV, Khelashvili G, Weinstein H. A New Computational Method for Membrane Compressibility: Bilayer Mechanical Thickness Revisited. Biophys J. 2019;116(3):487-502. doi:10.1016/j.bpj.2018.12.016

47. Gbenga BL, Taiwo Y. Studies of the Effect of Storage Conditions on Some Pharmaceutical Parameters of Powders and Tablets. Dhaka Univ J Pharm Sci. 2015;14(2):147-51. doi:10.3329/dujps.v14i2.28503

48. Patra CN, Pandit HK, Singh SP, Devi MV. Applicability and Comparative Evaluation of Wet Granulation and Direct Compression Technology to Rauwolfia serpentina Root Powder: A Technical Note. AAPS PharmSciTech. 2008;9(1):100-4. doi:10.1208/s12249-007-9015-7

49. Mahours GM, Shaaban DEZ, Shazly GA, Auda SH. The effect of binder concentration and dry mixing time on granules, tablet characteristics and content uniformity of low dose drug in high shear wet granulation. J Drug Deliv Sci Technol. 2017;39:192-9. doi:10.1016/j.jddst.2017.03.014 